\title{
Mechanism of the Anticoagulant Effect of Warfarin as Evaluated in Rabbits by Selective Depression of Individual Procoagulant Vitamin K-dependent Clotting Factors
}

\author{
Ariella Zivelin, L. Vijaya Mohan Rao, and Samuel I. Rapaport \\ Departments of Medicine and Pathology, University of California, San Diego, California 92093
}

\begin{abstract}
We have evaluated the contribution of depression of individual procoagulant vitamin $\mathrm{K}$-dependent clotting factors to the ability of warfarin to protect rabbits against tissue factor-induced coagulation. Mean activities of individual procoagulant factors were determined, in assays with rabbit substrates, for a group of rabbits achieving a protective degree of anticoagulation with warfarin. Values were: factor VII, $12 \%$; factor IX, 7\%; factor X, $14 \%$, and prothrombin, $13 \%$. The effect upon tissue factor-induced coagulation of selective immunodepletion of each factor to a comparable level was then evaluated. Immunodepletion of plasma factor $\mathrm{X}$ or prothrombin, but not of factor VII or factor IX, protected otherwise normal rabbits against tissue factorinduced coagulation. Next, we determined the effect upon the protection in warfarin-treated rabbits of selectively restoring factor $X$ or prothrombin before infusing tissue factor. When either factor was selectively restored, warfarin's protective effect was abolished. Moreover, selective restoration of prothrombin sensitized warfarin-treated rabbits to coagulation more severe than observed in nontreated control rabbits. One may extrapolate from these data that depression of both factor $\mathbf{X}$ and prothrombin are required for warfarin's clinical antithrombotic efficacy and that depression of plasma prothrombin is particularly important. (J. Clin. Invest. 1993. 92:21312140.) Key words: tissue factor • intravascular coagulation • factor VII • factor $\mathrm{X} \bullet$ prothrombin
\end{abstract}

\section{Introduction}

Warfarin and related vitamin $\mathrm{K}$ antagonists were used clinically for many years before it was recognized that they impaired not only the synthesis of procoagulant factors, factors VII, IX, X, and prothrombin, but also the synthesis of anticoagulant factors, protein C and protein S. Although warfarin's antithrombotic efficacy is established in a variety of clinical circumstances ( 1 ), it is not clear why in these circumstances the effect of depressing procoagulant factors outweighs the effect of depressing anticoagulant factors.

Address correspondence to Dr. Samuel I. Rapaport, UCSD Medical Center, Mail Code 8423, 200 West Arbor Drive, San Diego, CA 92103.

Ariella Zivelin's present address is Institute of Thrombosis and Hemostasis, Chaim Sheba Medical Center, Tel Hashomer, 52621, Israel; L. Vijaya Mohan Rao's present address is Department of Biochemistry, The University of Texas Health Center at Tyler, Tyler, TX 75710. 1993.

Received for publication 24 March 1993 and in revised form 3 June

J. Clin. Invest.

(c) The American Society for Clinical Investigation, Inc.

$0021-9738 / 93 / 11 / 2131 / 10 \$ 2.00$

Volume 92, November 1993, 2131-2140
In 1958, Sise et al. (2) observed that both hemorrhage and thrombosis in patients receiving a vitamin $\mathrm{K}$ antagonist were more closely related to specific plasma prothrombin activity than to the "prothrombin time," a test particularly sensitive to the effect of vitamin $\mathrm{K}$ antagonists upon plasma factor VII activity. Reports of venous thrombo-embolism in patients with hereditary factor VII deficiency $(3,4)$ also raised uncertainty as to the importance of depressed factor VII activity for warfarin's antithrombotic efficacy. Recently, Furie et al. (5) reported that the plasma native prothrombin antigen level correlated closely with the presence of bleeding or thromboembolic complications in patients given warfarin. Moreover, Xi et al. (6) have shown that adding purified prothrombin to pooled plasma from patients given a vitamin $\mathrm{K}$ antagonist increased thrombin generation whereas adding purified factors VII, IX, or X did not.

Only a few animal studies have been carried out on the mechanism of the antithrombotic effect of warfarin. Izak and Galewsky (7) reported in 1966 that treatment with warfarin failed to prevent intravascular coagulation in rabbits infused with a crude tissue factor (TF $)^{1}$ preparation. Wessler and colleagues (8-10), using a rabbit stasis thrombosis model, reported that warfarin protected against thrombosis not only by depressing factor VII initially and other vitamin K-dependent procoagulant factors after $2 \mathrm{~d}$ but also by enhancing, after $6 \mathrm{~d}$, an inhibitory activity in plasma against factor $\mathrm{Xa}$. There are no confirmatory studies in the literature of this last observation.

We report here studies in a rabbit model system of the contribution of the depression of each procoagulant vitamin $\mathrm{K}$-dependent clotting factor to warfarin's function as an anticoagulant agent. The data provide evidence for the importance of depression of both plasma prothrombin activity and plasma factor $\mathrm{X}$ activity for the ability of warfarin to protect rabbits against TF-induced intravascular coagulation.

\section{Methods}

\section{Reagents}

General. Sodium warfarin for intravenous administration was a gift from DuPont Pharmaceuticals (Willimgton, DE). Rabbit anti-human prothrombin antiserum and rabbit anti-human factor $\mathrm{X}$ antiserum were from American Bioproducts (Parsippany, NJ). Rabbit plasma for protein purification was purchased from Pel-Freez Biologicals (Rogers, AR).

Reagents for clotting assays. Rabbit brain thromboplastin (TF) was from Sigma Chemical Co. (St. Louis, MO). Automated APTT was from General Diagnostics (Morris Plains, NJ). Kaolin cephalin APTT Reagent was from Helena Laboratories (Beaumont, TX). Bovine thrombin and human fibrinogen reference plasma were from Baxter Diagnostics (Deerfield, IL). Human substrate plasmas deficient in a

1. Abbreviation used in this paper: $\mathrm{TF}$, tissue factor. 
specific clotting factor were from patients seen at the University of California, San Diego (UCSD) Medical Center, from George King Bio-Medical (Overland Park, KS), or were prepared by immunoadsorbing normal human plasma.

\section{Purified coagulation proteins}

Rabbit TF. Purified rabbit brain TF apoprotein (11) was reconstituted into phospholipid vesicles containing phosphatidylserine and phosphatidylcholine in a ratio of $4: 6(12)$ and stored at $-75^{\circ} \mathrm{C}$.

Rabbit factors VII, IX, X, and prothrombin. The initial steps of purification of rabbit vitamin $\mathrm{K}$-dependent clotting factors were essentially the same as for the human proteins $(13,14)$, but the elution profile from a DEAE-Sephadex column differed. Rabbit factor IX was eluted separately from the other clotting factors and was purified to homogeneity as described earlier (15). Prothrombin, factor VII, and factor X, which overlapped on elution from a DEAE-Sephadex column, were applied to a $5 \times 38$-cm heparin agarose column (14). The column was developed with an initial buffer $(0.02 \mathrm{M}$ sodium citrate, 1 $\mathrm{mM}$ benzamidine, $\mathrm{pH} 7.5$ ) to yield partially purified factor VII. Then, bound proteins were eluted with a linear salt gradient of $0-0.6 \mathrm{M} \mathrm{NaCl}$ in $0.02 \mathrm{M}$ citrate, $1 \mathrm{mM}$ benzamidine, $\mathrm{pH} 7.5$ (total gradient volume, $2,000 \mathrm{ml}$ ). This separated prothrombin from factor $\mathrm{X}$, yielding apparently homogeneous prothrombin and partially purified factor $\mathbf{X}$.

Human prothrombin and factor $X$. Human prothrombin and factor $\mathrm{X}$ were purified to apparent homogeneity as described earlier (14). As measured in chromogenic assays, the prothrombin preparation contained $<0.01 \%$ thrombin and the factor $\mathrm{X}$ preparation contained $<0.01 \%$ factor $\mathrm{Xa}(\mathrm{wt} / \mathrm{wt})$.

\section{Antibodies to rabbit clotting factors}

Anti-factor VII IgG. Partially purified rabbit factor VII was subjected to SDS-PAGE on a $10 \%$ polyacrylamide slab gel. The major stained protein band, which corresponded to the molecular weight of factor VII, was electroeluted and used as the antigen to immunize a goat as described earlier (15). The antiserum was heat inactivated at $56^{\circ} \mathrm{C}$ for $30 \mathrm{~min}$ and the IgG fraction was separated by precipitation at $40 \%$ ammonium sulfate saturation followed by DEAE-Aff-Gel blue chromatography. The IgG had a specific activity of $10-50$ inhibitor $U / \mathrm{mg}$ protein, bound strongly to rabbit factor VII on an immunoblot, and had no inhibitory activity against rabbit factors IX, X, or prothrombin. For this and subsequent antibodies, one inhibitor unit was defined as the concentration of IgG in an equal part mixture of IgG and rabbit plasma that inhibited $50 \%$ of the clotting factor activity in the mixture in 30-60 min at room temperature.

Anti-factor IX IgG. A mAb against rabbit factor IX (mAb 170.1) was prepared by standard techniques and purified by use of a $\mathrm{mAb}$ purification kit (Bio-Rad Laboratories, Richmond, CA). mAb 170.1 was of subclass IgGl, had an inhibitory activity of $200 \mathrm{U} / \mathrm{mg} \mathrm{IgG}$, and bound only to rabbit factor IX on an immunoblot of rabbit plasma. Monospecific polyclonal antibodies against rabbit factor IX were raised in a goat as described earlier (15).

Anti-factor $X I g G$. mAbs against rabbit factor $\mathrm{X}$ were prepared using standard techniques with partially purified rabbit factor $\mathrm{X}$ as an antigen and the $\mathrm{IgG}$ was purified as described above. $\mathrm{mAb} 409$ was used to prepare rabbit factor $\mathrm{X}$-deficient substrate plasma. Antibody $\mathrm{mAb} 541$, which was of subclass IgG3 and had a titer of $75 \mathrm{U} / \mathrm{mg} \mathrm{IgG}$, was injected into rabbits to immunodeplete plasma factor $\mathrm{X}$ activity.

Antiprothrombin IgG. Our purified rabbit prothrombin preparation lost most of its activity on overnight dialysis at $4^{\circ} \mathrm{C}$ into Hepes buffer. SDS-PAGE analysis of the dialyzed sample revealed a major protein band corresponding to prethrombin 1 . This band was electroeluted from a Coomassie blue-stained SDS-PAGE slab gel and used as antigen to raise a monospecific antiserum in a goat. The antiserum was affinity purified on a prethrombin 1 column that was prepared by coupling $300 \mathrm{mg}$ of rabbit prethrombin 1 to $25 \mathrm{ml}$ Affi-Gel 15 as described in the manufacturer's (Bio-Rad Laboratories) technical bulletin. About $100 \mathrm{ml}$ of antiserum was precipitated at $40 \%$ ammonium sulfate saturation. The precipitate was dissolved and dialyzed extensively in TBS, and mixed from $4 \mathrm{~h}$ to overnight with the immobilized prethrombin 1 at $4^{\circ} \mathrm{C}$. Unbound or weakly bound proteins were washed with TBS followed by $\mathrm{TBS}$ containing $1 \mathrm{M} \mathrm{NaCl}$. The bound $\mathrm{IgG}$ was eluted with $0.1 \mathrm{M}$ glycine, $\mathrm{pH} 2.4$, into test tubes containing 0.1 vol of $1.0 \mathrm{M}$ Tris. The eluted IgG was concentrated by precipitation with $80 \%$ ammonium sulfate saturation, dissolved, and dialyzed extensively in Hepes buffer. The affinity-purified IgG had a specific activity of 3 inhibitory $\mathrm{U} / \mathrm{mg}$ of protein.

Control IgG preparations. An anti-human thyroglobulin IgG that was unreactive against clotting factors was purified from ascitic fluid kindly provided by Dr. M. Zanetti (Department of Medicine, UCSD). Nonimmune goat IgG was purified as described above from commercial goat serum (Sigma Chemical Co.).

\section{Rabbit-specific deficiency substrate plasmas}

Rabbit substrate plasmas deficient in factor VII, IX, or X were prepared by immunoaffinity chromatography against goat anti-factor VII IgG, against a mixture of anti-factor IX mAb 170.1 and goat anti-factor IX IgG, and against anti-factor X mAb 409. In preparing the immunoadsorbant columns, the IgGs were coupled to Affi-Gel 15, 5 $\mathrm{mg}$ of $\mathrm{IgG} / \mathrm{ml}$ of beads, according to the manufacturer's instructions. Platelet-poor citrated rabbit plasma $(15-25 \mathrm{ml})$ was added to a 5-10$\mathrm{ml}$ specific antibody column and rotated on a mixer for $4-6 \mathrm{~h}$ at $4^{\circ} \mathrm{C}$. Factors VII and X substrate plasmas had $<1 \%$ activity of the specific factor. Factor IX substrate plasma had $\sim 3 \%$ residual factor IX activity. These substrate plasmas were stored at $-75^{\circ} \mathrm{C}$.

A serum reagent for use in specific rabbit and human prothrombin (factor II) assays was prepared by clotting either rabbit or human blood in a glass tube containing a 1:100-200 vol of rabbit brain TF (Sigma Chemical Co.). After 2-4 h the serum was separated from the clot by two successive centrifugations for $10 \mathrm{~min}$ at $10,000 \mathrm{~g}$, followed by dialysis of the serum into TBS. Serum so prepared contained $<1 \%$ prothrombin activity and $>60 \%$ activity of factors VII and X.

\section{Barium sulfate-adsorbed rabbit plasma}

Barium-adsorbed rabbit plasma, prepared as described earlier (16), was added in assays for factors VII, IX, and X to ensure that variation in levels of factors V and VIII in test samples did not influence the clotting times of these assays. Since the serum used in the prothrombin assay lacked fibrinogen, a special barium-adsorbed plasma reagent with a higher fibrinogen level was prepared for this assay from blood obtained from a rabbit given an intravenous injection of $100 \mu \mathrm{g} / \mathrm{kg}$ of Escherichia coli endotoxin (0111:B4; Sigma Chemical Co.) $24 \mathrm{~h}$ earlier.

\section{Animal experimental procedures}

Animal protocols. Female New Zealand rabbits (1.5-2.4 kg) were used in protocols approved by the Animal Subjects Committee of UCSD. Rectal temperatures, taken before and after an experiment to monitor against contamination of infused material with endotoxin, were unchanged.

Blood sampling, injections, and infusions. Blood samples of 1.5-2 $\mathrm{ml}$ were obtained by inserting a 23-gauge needle into a marginal ear vein that had been dilated by rubbing the ear with xylene. Nine parts of blood dripping freely from the hub were collected into an Eppendorf tube containing one part of a balanced citrate anticoagulant $(0.06 \mathrm{M}$ sodium citrate, $0.04 \mathrm{M}$ citric acid). Platelet-poor plasma was obtained by two successive centrifugations in an Eppendorf centrifuge for $6 \mathrm{~min}$ at $15,000 \mathrm{~g}$, at $4^{\circ} \mathrm{C}$. The plasma was stored in $\sim 0.2-\mathrm{ml}$ aliquots in plastic vials at $-75^{\circ} \mathrm{C}$. Blood for cell counts was collected into EDTAcoated microtainers (Fisher Scientific, Pittsburgh, PA). Larger amounts of blood for making rabbit reagents were obtained from a central ear artery.

TF was infused through a marginal ear vein as described earlier (12). Warfarin and $\mathrm{IgG}$ were injected either directly into a marginal ear vein through a 23-gauge butterfly set or into the tubing of a running infusion. In some experiments IgG was also added to the contents of an infusion bag to maintain an effective plasma level of IgG. 
Administration of warfarin. Rabbits were given a special diet depleted of vitamin K (ICN Biochemicals, Cleveland, $\mathrm{OH}$ ), beginning 3-4 $\mathrm{d}$ before warfarin in early experiments and beginning on day 1 of warfarin in later experiments. The rabbits were injected intravenously daily for a consecutive $5 \mathrm{~d}$ with $0.5 \mathrm{mg} / \mathrm{kg}$ of a $1-\mathrm{mg} / \mathrm{ml}$ stock solution of sodium warfarin in isotonic sterile saline. Blood samples were obtained daily to monitor warfarin treatment by a modified version of the Prothrombin and Proconvertin (P\&P) test of Owren and Aas (17).

TF-induced intravascular coagulation. Rabbits were infused over $\sim 4 \mathrm{~h}$ with $100 \mathrm{ml}$ of isotonic saline containing $\sim 20 \mathrm{ng} / \mathrm{ml}$ of reconstituted TF. The total TF infused was $1 \mu \mathrm{g} / \mathrm{kg}$. At an adjusted flow rate of $25 \mathrm{ml} / \mathrm{h}, \mathrm{TF}$, which had been injected into the infusion bag, began to enter the animal $\sim 30 \mathrm{~min}$ after the start of the infusion, i.e., after material from the infusion bag had replaced the saline in the infusion tubing. Intravascular coagulation was monitored by serial measurements of fibrinogen, factor V, and factor VIII. Unless otherwise stated, test results were expressed as percent of initial values obtained from a sample drawn before an infusion was started.

Five batches of TF were used. A first group of 15 control rabbits were infused with batch 1 or 2 . Fibrinogen, factor $\mathrm{V}$, and factor VIII levels were reduced to $\sim 50 \%$ by the end of the infusion, and one rabbit died shortly after the TF infusion was started. A second group of six control rabbits were infused with TF from batches 3,4 , or 5 , which turned out to be more potent. Fibrinogen, factor V, and factor VIII levels fell by $\sim 75 \%$, and three of the six animals died during the course of the infusion. Data from an experimental TF-infused group were always compared with data from the control group infused with TF of equivalent potency.

\section{Clotting factor assays}

Automated instruments yielding a photo-optical end point were used. Samples were tested in duplicate, and the mean was taken as the value for the specimen. Test plasmas were diluted for assay in cold TBS/BSA unless otherwise noted. Pooled citrated platelet-poor plasma from six to eight rabbits was used as a rabbit plasma reference standard with an assigned value of $100 \%$ for all factors except fibrinogen (see below). When plasma samples were assayed for activity after rabbits were given purified human factor $\mathrm{X}$ or prothrombin, clotting times were converted to percent activity of the factor from both a standard curve prepared with rabbit reference plasma and a standard curve prepared with a human reference plasma. Substrate plasmas for specific factor assays of rabbit plasma were: for factors VII, $\mathrm{X}$, and prothrombin, of rabbit origin; for factor IX, of human or rabbit origin; for factors $\mathrm{V}$ and VIII, of human origin.

The P\&P test. In the test as modified for this study, $100 \mu \mathrm{l}$ of rabbit plasma diluted 1:5 with barium sulfate-adsorbed rabbit plasma was incubated for $3 \mathrm{~min}$ at $37^{\circ} \mathrm{C}$ with $100 \mu \mathrm{l}$ rabbit brain TF (Sigma Chemical Co.). Clotting was triggered by the addition of $100 \mu \mathrm{l}$ of $25 \mathrm{mM}$ $\mathrm{CaCl}_{2}$, which in this and other tests cited below had been warmed to $37^{\circ} \mathrm{C}$.

Measurement of fibrinogen. The method of Clauss (18) was used. $100 \mu \mathrm{l}$ of $80 \mathrm{U} / \mathrm{ml}$ bovine thrombin was added to $200 \mu \mathrm{l}$ rabbit plasma diluted in Veronal buffer ( $28.4 \mathrm{mM}$ sodium barbital, $125 \mathrm{mM} \mathrm{NaCl}$, $\mathrm{pH} 7.35$ ). Clotting times were converted to fibrinogen concentration from a standard curve prepared with a human fibrinogen.

Factor $\mathrm{V}$ was measured in a one-stage assay in which $100 \mu \mathrm{l}$ of human immunodepleted factor $\mathrm{V}$-deficient plasma was incubated with $100 \mu \mathrm{l}$ of a 1:50-200 dilution of the test sample and $100 \mu \mathrm{l}$ rabbit brain TF (Sigma Chemical Co.) for $3 \mathrm{~min}$, and clotting was triggered by the addition of $100 \mu 125 \mathrm{mM} \mathrm{CaCl}$.

Factor VIII was measured in a one-stage assay in which $100 \mu \mathrm{l}$ of hereditary human factor VIII-deficient plasma, $100 \mu$ of a 1:10 or 1:20 dilution of test sample, and $100 \mu \mathrm{l}$ of APTT reagent were incubated for $5 \mathrm{~min}$, and clotting was triggered by the addition of $100 \mu \mathrm{l}$ of $30 \mathrm{mM}$ $\mathrm{CaCl}_{2}$.

Factor VII was measured in a one-stage assay in which $100 \mu \mathrm{l}$ of an equal part mixture of rabbit immunodepleted factor VII-deficient plasma and barium-adsorbed rabbit plasma, $100 \mu \mathrm{l}$ of a 1:50-200 dilu- tion of test plasma, and $100 \mu \mathrm{l}$ rabbit brain TF (Sigma Chemical Co.) were incubated together for $3 \mathrm{~min}$, and clotting was triggered by the addition of $100 \mu$ l of $25 \mathrm{mM} \mathrm{CaCl}_{2}$.

Factor $\mathrm{X}$ was measured essentially as for factor VII except that rabbit immunodepleted factor $\mathrm{X}$-deficient plasma was used as the substrate.

Prothrombin was measured in a one-stage assay in which $100 \mu l$ of an equal part mixture of rabbit serum reagent and special barium-adsorbed rabbit plasma, $100 \mu$ l of a 1:10-40 dilution of test plasma, and $100 \mu \mathrm{l}$ of rabbit brain TF (Sigma Chemical Co.) were incubated together for $3 \mathrm{~min}$, and clotting was triggered by the addition of $100 \mu \mathrm{l}$ of $25 \mathrm{mM} \mathrm{CaCl}_{2}$.

Factor IX was measured in a one-stage assay in which $100 \mu \mathrm{l}$ of an equal part mixture of rabbit immunodepleted factor IX-deficient plasma and barium adsorbed ox plasma or of human factor IX-deficient plasma and barium-adsorbed rabbit plasma, $100 \mu \mathrm{l}$ of a 1:5-10 dilution of test plasma, and $100 \mu \mathrm{l}$ of APTT reagent were incubated for $5 \mathrm{~min}$, and clotting was then triggered by the addition of $100 \mu \mathrm{l}$ of 35 $\mathrm{mM} \mathrm{CaCl}_{2}$. Very similar values were obtained with either substrate for rabbit plasma test samples when plasma factor IX activity was $<25 \%$, i.e., within the range critical for the present experiments.

\section{Electroimmunoassays}

Human prothrombin antigen and human factor $\mathrm{X}$ antigen were measured by electroimmunoassay (EIA) with specific antibodies in $1 \%$ Seakem agarose ME in a Tris-Tricine buffer, $\mathrm{pH} 8.6(81 \mathrm{mM}$ Tris- $\mathrm{HCl}$ and $24 \mathrm{mM}$ tricine). Antibody concentrations were $0.5 \%$ for rabbit anti-human prothrombin antiserum and $0.4 \%$ for rabbit anti-human factor $\mathrm{X}$ antiserum.

\section{Hematological tests}

Hematocrit and platelet counts were determined with a Coulter ST counter (Coulter Electronics Inc., Hialeah, FL) in the hematology laboratory of the UCSD Medical Center.

\section{Electrophoresis}

Reduced and nonreduced SDS-PAGE on $8-10 \%$ gels were performed according to the method of Laemmli (19). Proteins were transblotted onto Immobilon P membrane (Millipore, Bedford, MA) according to the method of Towbin et al. (20). Electroelution of protein bands from a stained SDS-PAGE was carried out with an electroelution system (Bio-Rad Laboratories) according to the manufacturer's instructions.

\section{Statistical methods}

All values reported in the tables are mean \pm SD and all values reported in the graphs are means \pm SEM. When data from two groups were compared, a two-tailed student's group $t$ test was used.

\section{Results}

The effect of warfarin upon rabbit vitamin $K$-dependent procoagulant factors. In an initial experiment with 13 rabbits given $0.5 \mathrm{mg} / \mathrm{kg}$ warfarin daily, animals were found to fall into two nonoverlapping groups. One group, referred to hereafter as high responders, had a mean P\&P activity on day 4 of warfarin of $17 \pm 8 \%$ (SEM). A second group, referred to hereafter as low responders, had a mean P\&P activity on day 4 of warfarin of $48 \pm 3 \%$ (SEM).

Activity levels of factors II, VII, IX, and X were measured daily for $\mathbf{4 d}$ in 23 high responder rabbits. Factor VII activity had fallen to its full extent by $24 \mathrm{~h}$, which was the time the first postwarfarin sample was drawn. Factors IX, X, and prothrombin were also reduced at $24 \mathrm{~h}$, but 2 to $3 \mathrm{~d}$ were required for factors IX and X to fall to their full extent, and $4 \mathrm{~d}$ were required for the fall in prothrombin activity to level off. Mean values for the P\&P test and for individual vitamin $\mathrm{K}$-depen- 
dent procoagulant factors from a large group of rabbits after $4 \mathrm{~d}$ of warfarin are listed in Table I. It is emphasized that these data were obtained in assays with rabbit substrates.

The effect of warfarin upon coagulation induced by the infusion of TF. Nine control non-warfarin-treated rabbits infused over $4 \mathrm{~h}$ with $1 \mu \mathrm{g} / \mathrm{kg}$ of TF (batch 1 ) had clear-cut evidence of intravascular coagulation (Fig. 1). By the end of the infusion mean values were $50 \%$ for fibrinogen, $35 \%$ for factor $\mathrm{V}$, and $42 \%$ for factor VIII. In six high responder warfarin-treated rabbits (mean P\&P test activity of $17 \pm 8 \%$ ) infused with the same batch of TF, intravascular coagulation was attenuated. By the end of the TF infusion mean values were $88 \%$ for fibrinogen, 93\% for factor V, and $80 \%$ for factor VIII (Fig. 1). These mean values differed from the mean values for the control rabbits $(P$ $<0.05$ for fibrinogen, and $P<0.001$ for factors V and VIII). In five low responder warfarin-treated rabbits (mean P\&P test activity of $48 \pm 3 \%$ ) infused with the $T F$, intravascular coagulation was only partially attenuated. By the end of the infusion mean values were $75 \%$ for fibrinogen, $50 \%$ for factor $\mathrm{V}$, and $43 \%$ for factor VIII (Fig. 1). Therefore, only high responder rabbits, with a P\&P test of between 5 and $35 \%$ after $4 \mathrm{~d}$ of warfarin, were used in further studies.

\section{Evaluation of the effect upon TF-induced intravascular coagulation of selective depression of factors VII, $I X, X$, and prothrombin}

Antibodies were administered to otherwise normal rabbits to depress selectively plasma activities of the vitamin $\mathrm{K}$-dependent procoagulant factors to levels similar to those obtained in high responder rabbits after $4 \mathrm{~d}$ of warfarin (Fig. 2). The rabbits were then infused with TF for $4 \mathrm{~h}$ and the degree of intravascular coagulation was compared to that observed in appropriate control groups.

The effect of different degrees of selective reduction of plasma factor VII activity upon TF-induced intravascular coagulation. 12 rabbits were injected with $\sim 250$ inhibitory $U$ of purified goat anti-rabbit factor VII IgG, and an additional 250 $\mathrm{U}$ of IgG were added to the infusion bag. The animals could be divided into two distinct groups. In one group of six animals, with a mean value for factor VII activity before immunodepletion of $95 \%$, the factor VII level fell to $10-15 \%$ (Fig. 2). In a second group of six rabbits, with a mean value for factor VII activity before immunodepletion of $56 \%$, the mean factor VII level fell to $<1 \%$.

Immunodepression of plasma factor VII activity to 10 $15 \%$, i.e., to a level comparable to the mean level obtained in rabbits given warfarin (Table I), failed to prevent TF-induced

Table I. Mean Values for the P\&P Test and Individual Vitamin $K$-dependent Procoagulant Factors in High Responder Rabbits after 4 d of Warfarin

\begin{tabular}{lccr}
\hline \multicolumn{1}{c}{ Assay } & $n$ & Activity \pm SD & Range \\
\hline & & $\%$ & $\%$ \\
P\&P & 38 & $16 \pm 8$ & $5-35$ \\
Factor II & 38 & $13 \pm 10$ & $3-54$ \\
Factor VII & 38 & $12 \pm 11$ & $0.5-50$ \\
Factor IX & 23 & $7 \pm 4$ & $2-25$ \\
Factor X & 38 & $14 \pm 7$ & $4-36$ \\
& & & \\
\hline
\end{tabular}

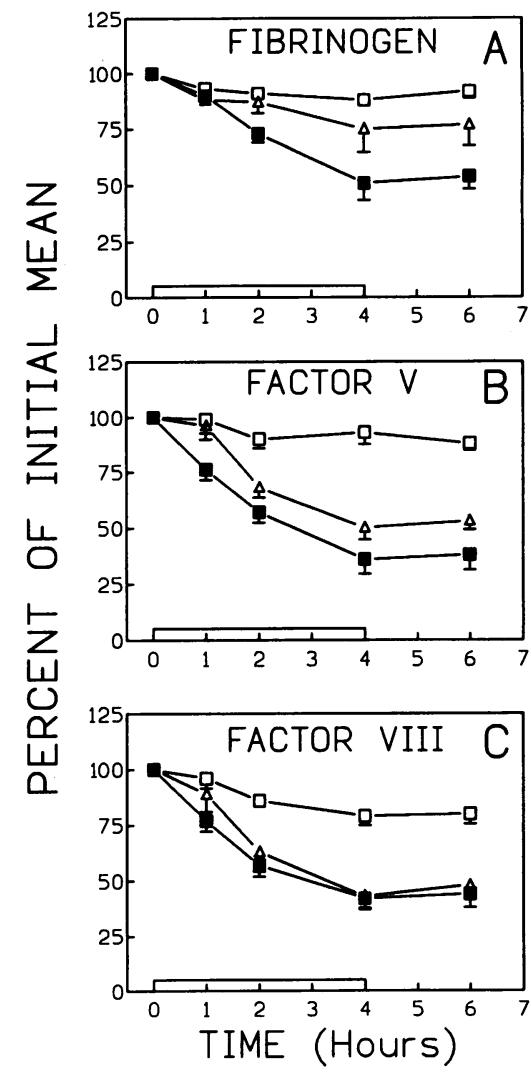

Figure 1. The effect of treatment with warfarin upon the extent of TFinduced intravascular coagulation as measured by the decrease in plasma levels of fibrinogen $(A)$, factor $\mathrm{V}(B)$, and factor VIII $(C)$. The infusion period is indicated by a bar. ( $\square$ ) High responders to warfarin treatment $(n=6)$; $(\Delta)$ low responders to warfarin treatment $(n$ $=5) ;(\square)$ control rabbits not treated with war-

farin $(n=9)$. Values are mean \pm SEM of the mean percent before infusion. Mean values at the end of the infusion for high responders and control animals differed: $P<0.05$ for fibrinogen and $P<0.001$ for factor V and VIII.

intravascular coagulation. By the end of a 4-h TF infusion mean values were $40 \%$ for fibrinogen, $33 \%$ for factor $\mathrm{V}$, and $31 \%$ for factor VIII. These values differed from the values observed in control warfarin-treated animals infused with TF but
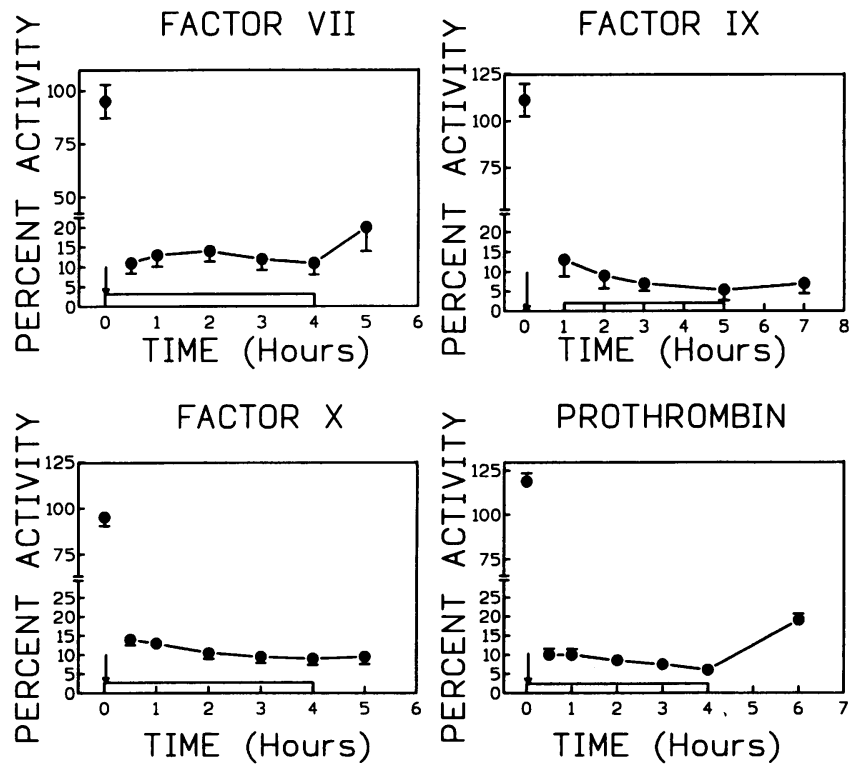

Figure 2. Specific immunodepletion of plasma levels of factors VII, IX, $\mathrm{X}$, and prothrombin to levels comparable to those obtained in high responder rabbits given warfarin. Specific antibodies were given $(\downarrow)$ after the initial blood sample was drawn. The animals were then infused with TF over the period indicated by the bar. Values are mean percent activity \pm SEM. Details are given in the text. 


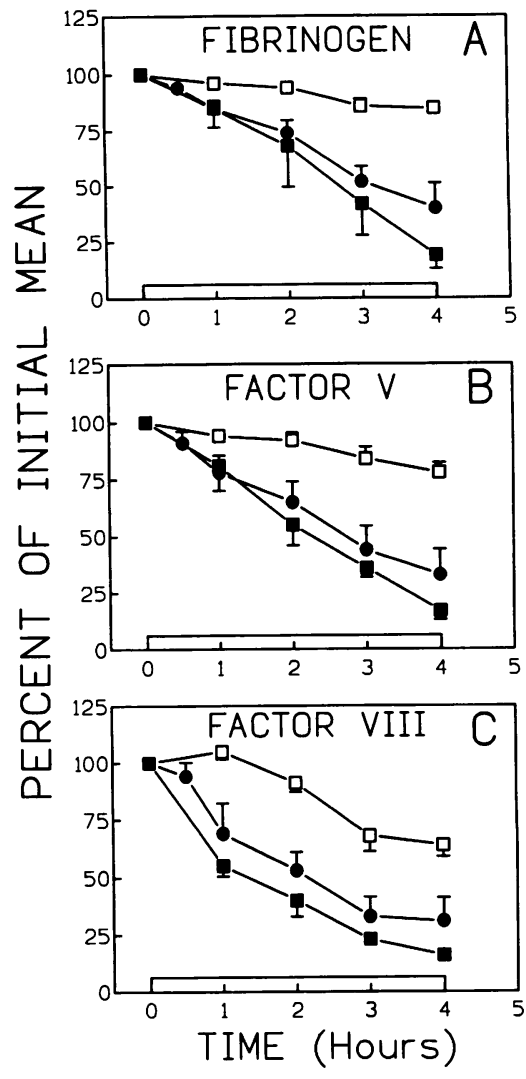

Figure 3. Evidence that selective depression of factor VII to $10-15 \%$ of normal plasma activity fails to prevent TF-induced intravascular coagulation as monitored by consumption of plasma fibrinogen $(A)$, factor $\mathrm{V}(B)$, and factor VIII $(C)$. Values are mean $( \pm$ SEM $)$ percent of the mean initial value. (•) Anti-factor VII-treated rabbits ( $n$ $=6) ;(\square)$ control rabbits $(n=3)$; ( $\square$ ) warfarintreated rabbits $(n=7)$. All rabbits were infused with TF over the period indicated by the bar.

not from the values observed in control nontreated animals infused with TF (Fig. 3).

In rabbits immunodepleted to plasma factor VII levels of $<1 \%$, a 4-h infusion of TF resulted in the following mean values: $85 \%$ for fibrinogen, $72 \%$ for factor $\mathrm{V}$, and $75 \%$ for factor VIII. Immunodepletion of plasma factor VII to $<1 \%$, in contrast to immunodepletion of plasma factor VII to $10-15 \%$, protected rabbits against TF-induced intravascular coagulation (Fig. 4).

The inability of selective reduction of plasma factor IX activity to protect against TF-induced intravascular coagulation. 12 rabbits were injected intravenously with $500 \mathrm{U} / \mathrm{kg}$ of monoclonal anti-factor IX IgG. $1 \mathrm{~h}$ later eight rabbits were infused with $\mathrm{TF}$ and four rabbits were infused with saline. Nine rabbits were injected with a control monoclonal anti-human thyroglobulin $\operatorname{IgG}(2.5 \mathrm{mg} / \mathrm{kg}) .1 \mathrm{~h}$ later five of these animals were infused with TF and the remaining four animals were infused with saline.

At $1 \mathrm{~h}$ after the anti-factor IX IgG injection the mean plasma factor IX activity of the animals given TF was $13 \%$, and by $2 \mathrm{~h}$ after the injection it had fallen to 7\% (Fig. 2). The latter was the same mean plasma activity as that found in a large group of rabbits given warfarin (Table I). By the end of the TF infusion mean values were $46 \%$ for fibrinogen, $40 \%$ for factor $\mathrm{V}$, and $42 \%$ for factor VIII (Fig. 5). These values did not differ from the values in animals infused with $T F$ after receiving the control monoclonal IgG. Thus, selective depletion of plasma factor IX activity to a level comparable to that measured in rabbits given warfarin failed to protect rabbits against TF-induced coagulation.

The protective effect of selective reduction of factor $X$ activity upon $T F$-induced intravascular coagulation. 11 rabbits were injected with $\sim 300$ inhibitory $U$ of monoclonal anti-factor $X$
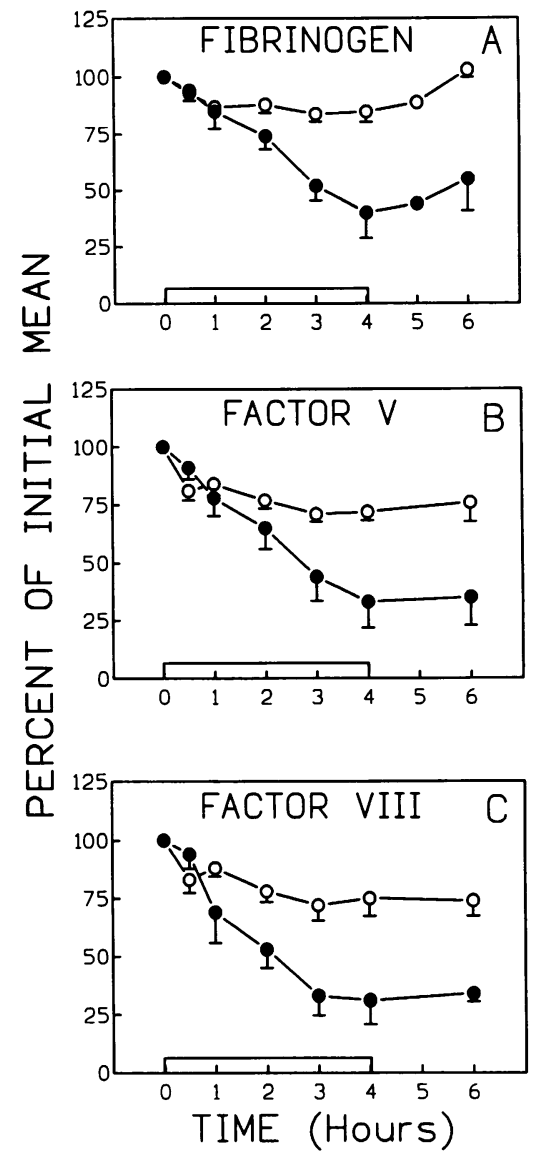

Figure 4. Evidence that immunodepression of factor VII to $<1 \%$ of normal plasma activity protects against TF-induced intravascular coagulation as monitored by consumption of fibrinogen $(A)$, factor $\mathrm{V}$ $(B)$, and factor VIII (C). Data from rabbits with selective depression of factor VII to $10-15 \%$ of normal plasma activity are also plotted for comparison. Values are mean ( \pm SEM) percent of the mean values before the injection of the IgG. (O) Rabbits with $<1 \%$ plasma factor VII activity $(n=6) ;(\bullet)$ rabbits with $10-15 \%$ plasma factor VII activity ( $n$ $=6$ ). The TF infusion period is indicated by the bar.

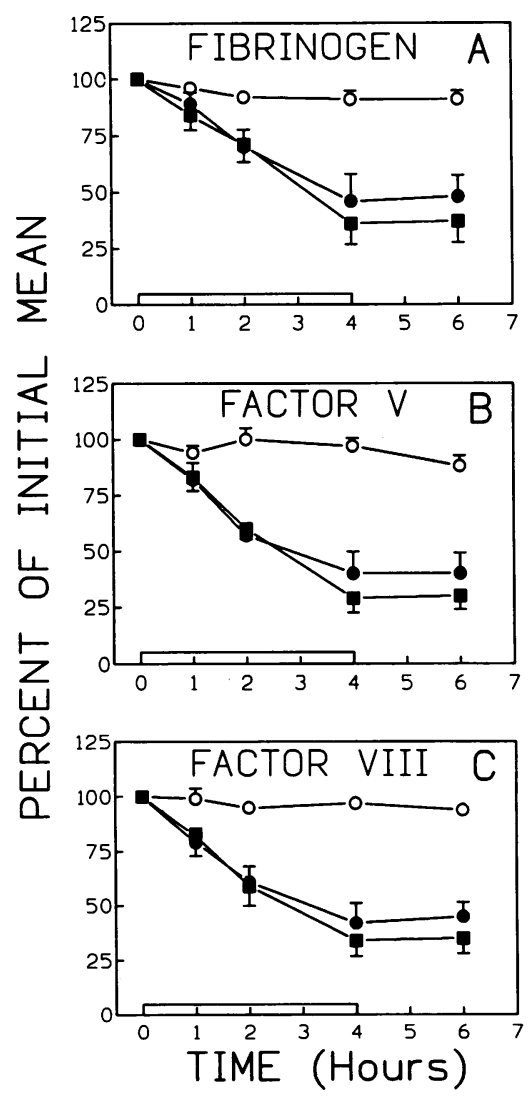

Figure 5. Evidence that selective immunodepression of plasma factor IX activity fails to prevent TF-induced intravascular coagulation as monitored by consumption of fibrinogen $(A)$, factor $\mathrm{V}(B)$, and factor VIII $(C)$. Values are mean $( \pm$ SEM $)$ percent of the mean initial values. (•) Rabbits receiving anti-IX IgG and infused with TF ( $n$ $=8)$; (匹) rabbits receiving control IgG and infused with $\mathrm{TF}(n=5)$; $(0)$ rabbits receiving either control $\operatorname{IgG}(n=4)$ or anti-IX IgG $(n=4)$ and infused with saline. The infusion period is indicated by the bar. 
IgG, and an additional 125-150 $\mathrm{U}$ was added to the infusion bag. Within $30 \mathrm{~min}$ of the initial injection factor $\mathrm{X}$ activity had fallen to $10-20 \%$ (Fig. 2), which was comparable to the mean $14 \%$ activity of high responder rabbits given warfarin (Table I). Seven of the rabbits were infused with TF, and the four remaining rabbits were infused with saline as controls. In the latter the anti-factor X IgG had no effect upon fibrinogen, factor $\mathrm{V}$, or platelets, but did alter the measurement of factor VIII as described below.

Selective immunodepletion of plasma factor $\mathrm{X}$ activity substantially protected the rabbits against TF-induced intravascular coagulation. At the end of the TF infusion the mean fibrinogen level was $81 \%$ (Fig. $6 \mathrm{~A}$ ), which differed from the $19 \%$ mean fibrinogen level of control rabbits infused with TF and was comparable to the $85 \%$ mean fibrinogen level of warfarin-treated rabbits infused with TF. At the end of the TF infusion the mean factor $V$ level was $68 \%$ (Fig. $6 \mathrm{~B}$ ), which differed from the mean factor $\mathrm{V}$ level of control nontreated rabbits infused with TF and was comparable to the $78 \%$ mean factor $\mathrm{V}$ activity of warfarin-treated rabbits infused with TF.

A problem became apparent in measuring plasma factor VIII levels in factor $\mathrm{X}$-depleted rabbit plasma. In contrast to the factor $\mathrm{V}$ assay, in which rabbit plasma test samples were assayed at a 1:50-200 dilution, test samples were assayed for factor VIII at a 1:20 dilution. Mean factor VIII levels in the first sample measured after the injection of anti-factor $\mathrm{X} \mathrm{IgG,}$ which was 30 min after beginning an infusion, were reduced

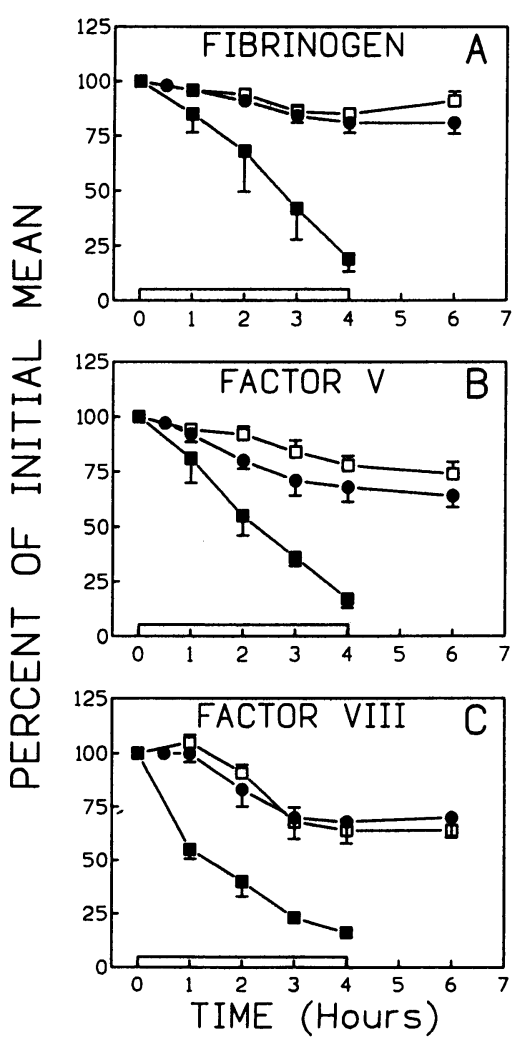

Figure 6. Evidence that selective immunodepression of plasma factor $\mathrm{X}$ activity to levels comparable to those obtained in high responders given warfarin protects against TF-induced intravascular coagulation as monitored by consumption of fibrinogen $(A)$, factor $\mathrm{V}$ $(B)$, and factor VIII $(C)$. The TF infusion period is indicated by the bar. ( $\bullet$ ) Nontreated control rabbits $(n=3)$; (ם) warfarin-treated rabbits $(n=7)$; $(\bullet)$ rabbits treated with anti-factor X IgG ( $n$ $=7$ ). Values are mean percent $( \pm$ SEM) of mean initial values for fibrinogen and factor $\mathrm{V}$ and mean percent of the sample $30 \mathrm{~min}$ after injection of IgG for factor VIII. At the end of the TF infusion the $P$

values for differences in means for the anti-X/TF animals and the warfarin / TF animals were: for fibrinogen, $P=0.46$; for factor V, $P$ $=0.22$; for factor VIII, $P=0.73$. The corresponding $P$ values for differences in means for the anti-X/TF animals and the control/TF animals were: for fibrinogen, $P<0.0001$; for factor $\mathrm{V}, P=0.001$; for factor VIII, $P=0.012$. both for animals infused with saline ( $56 \pm 6 \%$ ) and for animals infused with TF $(66 \pm 6 \%)$. Since the anti-rabbit factor X IgG did not inhibit human factor $\mathrm{X}$ in the factor VIII-deficient substrate plasma, it appeared that a markedly reduced factor $\mathrm{X}$ level in a rabbit plasma test sample relative to the factor $\mathrm{X}$ level of the rabbit plasma reference standard influenced the test result of our factor VIII assay.

Therefore, in the analysis of the factor VIII data, the factor VIII level $30 \mathrm{~min}$ after beginning an infusion of TF, rather than the factor VIII level before injecting the anti-factor X IgG, was assigned a value of $100 \%$. When the data were plotted as percent of this initial value (Fig. $6 C$ ), the mean plasma factor VIII level at the end of the TF infusion differed from the mean factor VIII level of control rabbits infused with TF and was comparable to the mean factor VIII level of warfarin-treated rabbits infused with TF. Thus, all data were consistent in establishing that selective depression of factor $\mathrm{X}$ to a level comparable to that obtained in high responder rabbits given warfarin protected against TF-induced intravascular coagulation in our rabbit model.

The protective effect of selective reduction of plasma prothrombin activity upon TF-induced intravascular coagulation. 10 rabbits were injected with $\sim 150$ inhibitory $U$ of affinity purified goat anti-rabbit prothrombin IgG, and an additional $75 \mathrm{U}$ of IgG was added to the infusion bag. In six rabbits the mean prothrombin activity fell to $10 \%$ (Fig. 2), which was comparable to the $13 \%$ activity of high responder rabbits given warfarin (Table I). These rabbits were infused with TF. Three rabbits, in which the plasma prothrombin activity fell to between 2 and 3\%, and a fourth rabbit with a plasma prothrombin activity of $11 \%$ were infused with saline as a control for the effect of the injection of the IgG upon hemostatic factors and their measurement.

Mean values for fibrinogen at the end of a 4-h infusion were 93\% for control prothrombin-depleted animals infused with saline, $19 \%$ for control non prothrombin-depleted animals infused with TF, and $75 \%$ for prothrombin-depleted animals infused with TF. This last value was comparable to the $85 \%$ mean fibrinogen level of warfarin-treated animals infused with TF (Fig. $7 A$ ). Mean values for factor V (Fig. $7 B$ ) at the end of a 4-h infusion were $79 \%$ for control prothrombin-depleted animals infused with saline, $17 \%$ for control non-prothrombindepleted rabbits infused with TF, $61 \%$ for prothrombin-depleted animals infused with TF, and $78 \%$ for warfarin-treated animals infused with TF. Although the mean value for factor $V$ of the prothrombin-depleted rabbits given TF was lower than the value for factor $\mathrm{V}$ of the warfarin-treated animals $(P$ $=0.012$ ), it was impressively higher than the value for the control TF-infused rabbits $(P<0.0005)$.

The data on factor VIII levels were less clear cut (Fig. $7 C$ ). Mean factor VIII levels fell $30 \mathrm{~min}$ after injection of antiprothrombin IgG to $70-75 \%$ of mean values before the injection in both animals infused with TF and in animals infused with saline. At the end of infusion the mean factor VIII level was lower for the animals infused with TF than for the animals infused with saline $(P=0.004)$. It was also lower than for the warfarin-treated animals infused with TF $(P=0.008)$. However, the mean factor VIII level for the prothrombin-depleted rabbits infused with TF was higher than for the control rabbits infused with TF $(P=0.003)$.

In contrast to the injection of the other IgG preparations, the injection of the anti-rabbit prothrombin IgG caused a $50 \%$ 

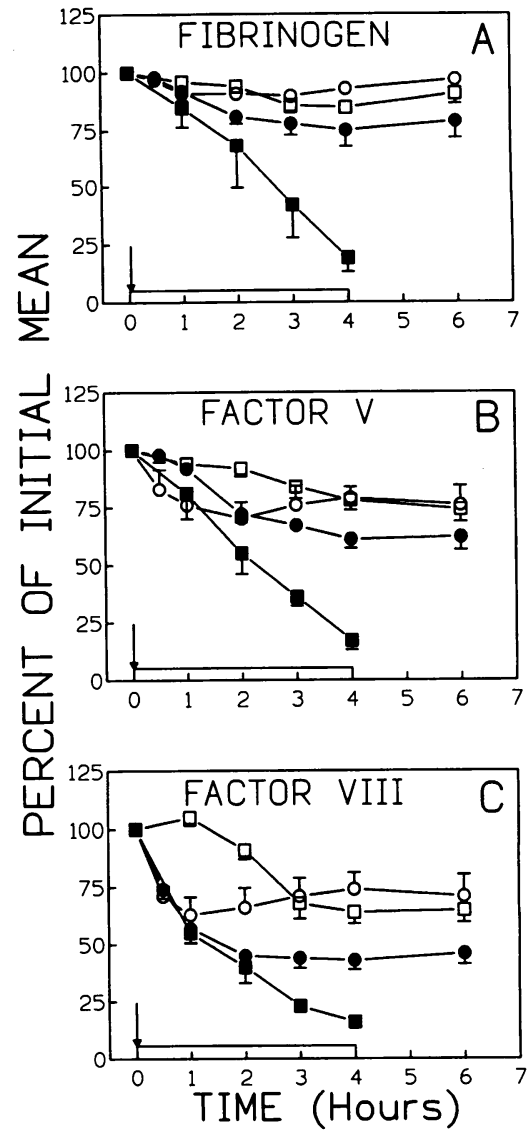

Figure 7. Evidence that selective immunodepression of plasma prothrombin activity to levels comparable to those obtained in high responders given warfarin protects against TF-induced intravascular coagulation as monitored by consumption of fibrinogen $(A)$, factor $\mathrm{V}(B)$, and factor VIII $(C)$. (•) Rabbits given antiprothrombin IgG and infused with TF ( $n$ $=6$ ); ( $\square$ ) warfarintreated rabbits infused with $\mathrm{TF}(n=7)$; ( $(-)$ control nontreated rabbits infused with TF ( $n$ $=3$ ); (O) control rabbits given antiprothrombin IgG and infused with saline ( $n$ $=4)$. Values are mean percent $( \pm$ SEM $)$ of mean initial values before the IgG injection $(\downarrow)$, or before the infusion. The infusion period is indicated by the bar. At the end of the

TF infusion the $P$ values for differences between means for anti-II/TF and warfarin / TF animals were: for fibrinogen, $P=0.2$; for factor $\mathrm{V}$, $P=0.012$; for factor VIII, $P=0.008$. The corresponding $P$ values for differences between means of anti-II/TF animals and control/TF animals were: for fibrinogen, $P=0.002$; for factor $\mathrm{V}, P<0.0005$; for factor VIII, $P=0.003$.

fall in the mean platelet count of both rabbits infused with saline and rabbits infused with TF (Table II). Because plasma prothrombin concentration exceeds by many-fold the concentrations of factors VII, IX, or X, the platelet fall after antiprothrombin IgG is presumed to stem from the binding of large enough amounts of prothrombin-antiprothrombin immune complexes to platelets to cause platelet sequestration. After $2 \mathrm{~h}$, platelet counts began to rise both in rabbits infused with saline and in rabbits infused with TF, which indicated that sufficient thrombin had not been generated in the rabbits infused with TF to depress the platelet count further.

Viewed as a whole the above data on fibrinogen, factor $\mathrm{V}$, factor VIII, and platelets provide convincing evidence that selective immunodepletion of plasma prothrombin activity substantially protected rabbits against TF-induced intravascular coagulation.

Selective restoration of factor $X$ in warfarin-treated rabbits infused with $T F$. It was clear from the data above that immunodepletion of either plasma factor $\mathrm{X}$ or prothrombin to activities comparable to those obtained in warfarin-treated rabbits sufficed to protect otherwise normal rabbits against TF-induced intravascular coagulation. Our next step was to determine the effect of selective restoration of factor $\mathrm{X}$ upon the protection warfarin afforded against TF-induced intravascular coagulation.
Table II. Mean Platelet Count of Rabbits Given Antiprothrombin IgG and Infused with Either TF or Saline

\begin{tabular}{lcc}
\hline & \multicolumn{2}{c}{ Mean platelet count } \\
\cline { 2 - 3 } Time & \multicolumn{3}{c}{ TF infusion $(n=6)$} & Saline infusion $(n=4)$ \\
\hline & \multicolumn{3}{c}{$\times 10^{9} /$ liter $\pm S D$} \\
$0 \mathrm{~h}^{*}$ & $520 \pm 125$ & $586 \pm 151$ \\
$30 \mathrm{~min}$ & $263 \pm 70$ & $270 \pm 144$ \\
$2 \mathrm{~h}$ & $374 \pm 80$ & $363 \pm 122$ \\
$4 \mathrm{~h}$ & $393 \pm 84$ & $381 \pm 126$ \\
\hline
\end{tabular}

* Before IgG and the beginning of an infusion

Since it was necessary to use purified human factor $\mathrm{X}$ for this purpose, in a preliminary experiment, $1 \mathrm{U}$ of human factor $\mathrm{X}$ was added in vitro to $1 \mathrm{ml}$ of rabbit factor $\mathrm{X}$-deficient plasma, and the resultant plasma factor $\mathrm{X}$ activity was assayed with rabbit factor $\mathrm{X}$-deficient substrate. The following values were obtained: $100 \%$, when clotting times were converted to percent activity from a human plasma reference curve; only $10-15 \%$, when clotting times were converted to percent activity from a rabbit plasma reference curve. As evaluated in a onestage factor $\mathrm{X}$ assay with rabbit reagents, human factor $\mathrm{X}$ had a much lower activity in rabbit plasma than did rabbit factor $X$.

Because of this observation, three warfarin-treated rabbits were injected with $400-500 \mathrm{U}$ of purified human factor $\mathrm{X}$ before infusing TF. This raised the mean initial plasma factor $X$ activity of $19 \%$ to $57 \%$ as read from a rabbit reference plasma curve, and to $600 \%$ as read from a human plasma reference curve (Fig. 8). The mean plasma human factor $\mathrm{X}$ antigen level after the injection was 475\%. By the end of the 4-h TF infusion mean plasma factor $\mathrm{X}$ activity had fallen to $25 \%$ as read from a rabbit reference curve, and to $220 \%$ as read from a human reference curve.

The 4-h infusion of TF resulted in a fall of mean plasma fibrinogen level to $19 \%$ and mean plasma factor $V$ level to $16 \%$. These mean values were identical to those observed in three TF-infused control rabbits not given warfarin. The mean plasma factor VIII activity fell to an intermediate value of $37 \%$, which was higher $(P=0.011)$ than the mean factor VIII level of $16 \%$ in the control rabbits not given warfarin but lower $(P$ $=0.010$ ) than the mean factor VIII level of $64 \%$ in seven warfarin-treated rabbits not injected with factor $\mathrm{X}$.

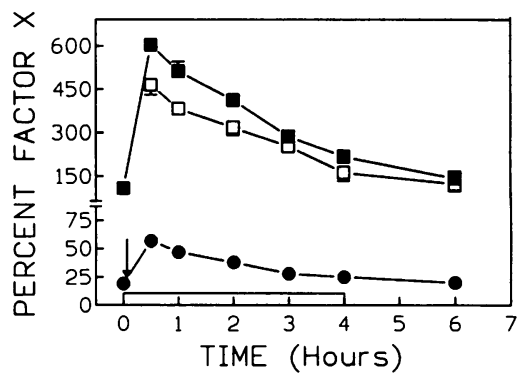

Figure 8. Mean plasma factor $\mathrm{X}$ levels in three warfarin-treated rabbits injected with human factor $\mathrm{X}$ and infused with TF. Values are percent \pm SEM. $(\bullet)$ Factor $\mathrm{X}$ activity measured with rabbit substrate and read from a rabbit plasma reference curve; (a) factor X activity measured with rabbit substrate and read from a human plasma reference curve; ( $\square$ ) human factor $X$ antigen measured in an EIA with rabbit anti-human factor $\mathbf{X}$ antiserum. The injection of the human factor $\mathrm{X}$ is indicated by the arrow and the infusion period by the bar. 
These data provided evidence that restoring plasma factor $\mathrm{X}$ activity in warfarin-treated rabbits could abolish the protection warfarin afforded against TF-induced intravascular coagulation. Despite the low concentration of prothrombin activity in the warfarin-treated animals (range, 6-25\%), sufficient thrombin was generated to induce intravascular coagulation as extensive as that observed in control non-warfarin-treated rabbits.

Selective restoration of prothrombin in warfarin-treated rabbits infused with $T F$. Eight warfarin-treated rabbits were injected with $\sim 75 \mathrm{U} / \mathrm{kg}$ of human prothrombin. Three rabbits were infused with saline as controls and five rabbits were infused with TF, but, as described below, data from one were excluded. In the remaining four rabbits the mean plasma prothrombin activity $1 \mathrm{~h}$ after the injection of prothrombin was $134 \pm 21 \%$, and the mean plasma human prothrombin antigen was $124 \pm 21 \%$. Mean activities of the other procoagulant vitamin $\mathrm{K}$-dependent factors in these four rabbits on the day of the experiment were: factor VII, $14 \%$; factor IX, $6 \%$; and factor $\mathrm{X}, 15 \%$.

$1 \mathrm{~h}$ after the injection of prothrombin, which was just before beginning an infusion of TF or saline, the platelet count and fibrinogen levels were unchanged but mean values in percent of initial values were slightly elevated for both factor $\mathrm{V}$ $(133 \pm 29 \%)$ and factor VIII $(125 \pm 34 \%)$. Since our purified prothrombin contained a trace of thrombin $(<0.01 \%)$, it is possible that there were traces of circulating thrombin-activated factors $\mathrm{V}$ and VIII in these animals.

Restoring plasma prothrombin activity not only reversed the protection by warfarin but strikingly sensitized the rabbits to TF-induced intravascular coagulation. Plasma fibrinogen, factor V, and factor VIII fell dramatically during the TF infusion (Fig. 9). The first rabbit died of uncontrollable bleeding secondary to defibrination after a 1-h sample was taken, and its data were excluded. A second rabbit died after a sample at $2 \mathrm{~h}$ was taken, and the data from this animal were included. In the remaining three animals the TF infusion was stopped within 2 to $3 \mathrm{~h}$ because of persisting oozing of blood from the sampling sites. As can be seen in Fig. 9, plasma fibrinogen levels fell within $2 \mathrm{~h}$ to unmeasurable levels $(<25 \mathrm{mg} / \mathrm{dl}$ ), and factor $\mathrm{V}$ and VIII mean activities were $<5 \%$. In addition, the mean platelet count fell from an initial value of $759 \times 10^{9} /$ liter to $100 \times 10^{9} /$ liter after $2 \mathrm{~h}$ of TF infusion.

Hematologic parameters. The mean hematocrit value for the 64 rabbits fell as a consequence of infusions and blood sampling from an initial value of 36 to $33 \%$ at the end of the infusion period. The fall in an animal's hematocrit was independent of whether the animal experienced intravascular coagulation. In 22 rabbits with intravascular coagulation, the mean platelet count decreased from an initial value of $634 \pm 127$ $\times 10^{9} /$ liter to a value of $388 \pm 151 \times 10^{9} /$ liter at the end of a 4-h TF infusion $(P<0.001)$. In 32 animals without intravascular coagulation, mean platelet levels were unchanged after a 4-h infusion. The data from 10 animals in which, as mentioned earlier, platelet counts fell after the injection of antiprothrombin IgG were excluded in calculating these means (Table II).

\section{Discussion}

The experiments reported here provide data on how warfarin functions in vivo as an anticoagulant when TF was used to initiate blood coagulation (21). In a preliminary experiment

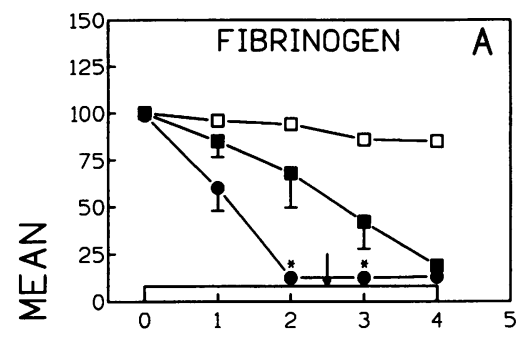

Figure 9. Evidence that selective restoration of prothrombin in warfarin-treated rabbits sensitizes the rabbits to extensive TF-induced intravascular coagulation as monitored by consumption of fibrinogen $(A)$, factor $\mathrm{V}(B)$, and factor VIII $(C)$. Values are mean ( \pm SEM) percent of the mean values before the injection of human prothrombin or before the beginning of the infusion in the other groups. All rabbits were infused with TF. (•) Warfarin-treated rabbits with restored prothrombin $(n=4)$; (a) control nontreated rabbits $(n$ = 3); (ם) warfarintreated rabbits not given prothrombin $(n=7)$. The infusion period for the control groups is indicated by the bar. The arrow denotes the end of the mean infusion period for the experimental group. The asterisk denotes an unmeasurable fibrinogen level of $<25 \mathrm{mg} / \mathrm{dl}$.

the response of rabbits to $0.5 \mathrm{mg} / \mathrm{kg}$ of sodium warfarin given intravenously daily for $4 \mathrm{~d}$ was determined as monitored by a sensitive prothrombin time technique (a modification of the P\&P test [17]). The rabbits fell into two groups: high responders, in which the mean plasma P\&P activity decreased to $17 \%$, and low responders, in which the mean plasma P\&P activity decreased to only $48 \%$. The reason is unknown, but a difference in responsiveness to warfarin of rabbits has also been noted by others (22). Contrary to a single early report that warfarin treatment failed to prevent intravascular coagulation in rabbits infused with crude TF (7), under our experimental conditions high responder rabbits were protected against TFinduced intravascular coagulation (Fig. 1).

The P\&P activity range of $5-35 \%$ of protected high responder rabbits is similar to the $10-30 \%$ range first recommended as the therapeutic range for patients monitored with the P\&P test (23). Moreover, the mean P\&P activity of our high responder rabbits of $16 \%$ is comparable to the $15 \% \mathrm{P} \& \mathrm{P}$ activity later recommended for anticoagulant therapy in patients with arterial disease (24). In our opinion, this reinforces the validity of extrapolating data from our rabbit model to an understanding of the mechanism of the clinical antithrombotic efficacy of warfarin.

An initial approach was to determine the effect upon TFinduced coagulation of selective immunodepletion of factors VII, IX, X, and prothrombin to mean levels comparable to those obtained in high responder rabbits given warfarin (Table I). It was thought important to measure the activity of the procoagulant vitamin $\mathrm{K}$-dependent factors as they functioned in rabbit plasma. Specific rabbit substrate plasmas for each factor were prepared and assays using these substrates were 
standardized. As documented elsewhere (25) this proved essential for accurate determination of the plasma activity of factors VII, X, and prothrombin.

Selective immunodepletion of plasma factor VII activity to a mean level (11\%) comparable to that obtained in high responder rabbits given warfarin ( $12 \%)$ failed to protect against TF-induced intravascular coagulation (Fig. 3). We infer from this experimental result that the fall in plasma factor VII activity in patients treated with warfarin, e.g., to the $20 \%$ level observed in a group of patients stably anticoagulated with a vita$\min \mathrm{K}$ antagonist (26), contributes little if any to warfarin's antithrombotic efficacy.

Additional observations support this conclusion. As mentioned earlier, venous thromboembolism has been reported in patients with hereditary factor VII deficiency $(3,4)$. Adding purified factor VII to a plasma level of $5 \%$ generated maximal prothrombinase activity when the coagulation reactions of hereditary factor VII-deficient plasma were initiated in vitro with dilute TF (6). Finally, a plasma factor VII level of between 5 and $10 \%$ has been reported to be adequate for surgical hemostasis in patients with hereditary factor VII deficiency $(27,28)$.

As expected, since TF initiates coagulation through the formation of factor VII(a)/TF complexes, selective immunodepletion of plasma factor VII activity to $<1 \%$ protected the rabbits against TF-induced intravascular coagulation (Fig. 4). However, the intensity of warfarin therapy needed to achieve an antithrombotic effect from such severe depletion of plasma factor VII activity would have an unacceptable risk of clinical bleeding.

Selective immunodepression of plasma factor IX to levels comparable to the $7 \%$ mean level of high responder rabbits given warfarin also failed to protect rabbits against TF-induced intravascular coagulation (Fig. 5). Therefore, in at least some clinical circumstances depression of plasma factor IX activity may not contribute significantly to the antithrombotic efficacy of warfarin. However, it is premature to conclude that depression of factor IX activity fails to contribute to the antithrombotic efficacy of warfarin when coagulation is initiated by a lower concentration of TF or by factor XIa. Further data are needed but may not be obtainable with the present model system, which is insensitive to infusion of concentrations of TF much lower than $1 \mu \mathrm{g} / \mathrm{kg}(29)$.

In contrast to the above, selective immunodepression of either factor X (Fig. 6) or prothrombin (Fig. 7) to mean levels comparable to those observed in high responder rabbits given warfarin (Table I) protected rabbits against TF-induced intravascular coagulation. These observations in otherwise normal rabbits prompted us to carry out additional experiments to determine whether depression of factor $\mathrm{X}$ alone or prothrombin alone would also protect against TF-induced coagulation in warfarin-treated animals, in which protein $\mathrm{C}$ and $\mathrm{S}$ levels are depressed. Therefore, either plasma factor $\mathrm{X}$ or prothrombin was restored in high responder rabbits given warfarin before they were infused with TF. Because highly purified rabbit factor $\mathrm{X}$ and rabbit prothrombin were not available in sufficient quantity for these experiments, purified human proteins had to be used.

The injection of 400-500 U of human factor X into a 2-kg rabbit, which, as discussed earlier, raised the animal's plasma factor $\mathrm{X}$ level from $\sim 20 \%$ to only $\sim 60 \%$ as determined from a rabbit plasma reference curve, reversed the protection warfarin afforded against TF-induced intravascular coagulation.
Despite a mean plasma prothrombin activity of only $15 \%$, manifestations of intravascular coagulation in these animals were virtually indistinguishable from those observed when TF was infused into control animals with a normal plasma prothrombin level.

However, the effect of restoring factor $\mathrm{X}$ in these experiments must be evaluated with the caveat that the test result in our one-stage rabbit factor $\mathrm{X}$ assay is determined by the initial rates, over seconds after recalcifying the reaction mixture, of the generation and function of human factor $\mathrm{Xa}$ in rabbit plasma. Because these initial rates are slower than if the sample contained an equivalent concentration of rabbit factor $\mathrm{X}$, clotting times converted to percent activity from a rabbit plasma reference curve will yield a much lower value for factor $X$ activity than clotting times converted to percent activity from a human plasma reference curve. It is possible that the large amounts of human factor $\mathrm{X}$ that were injected into rabbits, which raised plasma levels to $\sim 600 \%$ as measured with a human plasma reference standard (Fig. 8), could have had much more of a procoagulant effect over the $4 \mathrm{~h}$ of a TF infusion than one might assume from the $\sim 40 \%$ increase in plasma factor $X$ concentration that was measured with a rabbit plasma reference standard.

Restoring prothrombin in high responder rabbits given warfarin not only reversed warfarin's protection but sensitized the animals to TF-induced intravascular coagulation (Fig. 9). In contrast to the protection seen in rabbits immunodepleted of plasma factor $\mathrm{X}$, the comparably low factor $\mathrm{X}$ activity of warfarin-treated animals with restored prothrombin failed to prevent massive TF-induced intravascular coagulation with uncontrollable bleeding due to defibrination. It is assumed that this reflected an inability of depressed protein $\mathrm{C}$ and $\mathrm{S}$ levels to regulate the TF-induced coagulation. It is also believed that the difference between reversing protection by restoring factor $\mathrm{X}$ and enhancing intravascular coagulation by restoring prothrombin reflects prothrombin's role as the substrate for thrombin.

In the present experiments the prevention of a fall in plasma fibrinogen, factor V, and factor VIII levels has been taken as evidence for reduced TF-induced intravascular coagulation. Although unquestionably true for fibrinogen, one could question whether the maintenance of factor V and VIII levels in warfarin-treated animals infused with TF could have resulted at least in part from reduced plasma protein $\mathrm{C}$ and $\mathrm{S}$ levels. This seems most unlikely to us in view of the striking depletion of plasma factor V and VIII observed after TF infusion in warfarin-treated animals with restored prothrombin.

The prothrombin time test is sensitive to the combined activity of factor VII, factor X, and prothrombin. However, when warfarin is given to a patient the initial prolongation of the prothrombin time stems primarily from a reduced plasma factor VII activity, since factor VII has an intravascular half-clearance time of only $5 \mathrm{~h}(30)$. Although an initial fall in plasma factor VII to levels of $10-15 \%$ within 1-2 d of starting warfarin therapy may yield a prothrombin time in the accepted therapeutic range, yet, as strongly supported by the data here, a patient will not be protected against thrombosis. Indeed, because protein $\mathrm{C}$ also has a similarly short intravascular halfclearance time (31), the prolonged prothrombin time during the first day or two of treatment with warfarin is thought to mask an initial period of potential hypercoagulability.

One may infer from our data that maximal antithrombotic 
efficacy of warfarin in patients will not be obtained until both plasma factor $\mathrm{X}$ activity and plasma prothrombin activity are substantially depressed. In particular, our data provide impressive in vivo evidence of the key importance of depression of prothrombin activity for warfarin's anticoagulant effect. It is increasingly recognized $(32,33)$ that when patients are given both heparin and warfarin for treatment of an acute thrombotic episode, the heparin should be continued for several days after starting the warfarin regardless of the prothrombin time. In view of the intravascular half-clearance time in humans for factor X of $\sim 40 \mathrm{~h}$ (34) and for prothrombin of $\sim 60 \mathrm{~h}$ (34), it seems appropriate to us to extend the period of overlap to $6 \mathrm{~d}$ in patients with evidence of extensive venous thrombosis. A clinical study in which prothrombin levels are measured, either as specific prothrombin activity or as native prothrombin antigen $(5,35)$, before heparin is discontinued should provide the information needed to validate the above recommendation.

\section{Acknowledgments}

We acknowledge the expert technical assistance of Mr. An D. Hoang.

This work was supported by National Heart Lung and Blood Institute (NHLBI) grants HL-27234 (to S. I. Rapaport) and HL-42813 (to L. V. M. Rao). L. V. M. Rao is a recipient of a Research Career Development Award from NHLBI.

\section{References}

1. Hirsh, J. 1991. Oral anticoagulant drugs. N. Engl. J. Med. 324:1865-1875. 2. Sise, H. S., S. M. Lavelle, D. Adamis, and R. Becker. 1958. Relation of hemorrhagic and thrombosis to prothrombin during treatment with coumarintype anticoagulants. $N$. Engl. J. Med. 259:266-271.

3. Godal, H. C., K. Madsen, and R. Nissen-Meyer. 1962. Thrombo-embolism in patients with total proconvertin (factor VII) deficiency. A report on two cases. Acta Med. Scand. 171:325-327.

4. Hall, C. A., S. I. Rapaport, S. B. Ames, and J. A. Degroot. 1964. A clinical and family study of hereditary proconvertin (factor VII) deficiency. Am. J. Med. 37:172-181.

5. Furie, B., C. F. Diuguid, M. Jacobs, D. L. Diuguid, and B. C. Furie. 1990. Randomized prospective trial comparing the native prothrombin antigen with the prothrombin time for monitoring oral anticoagulant therapy. Blood. 75:344349.

6. Xi, M., S. Beguin, and H. C. Hemker. 1989. The relative importance of the factors II, VII, and X for the prothrombinase activity in plasma of orally anticoagulated patients. Thromb. Haemostasis. 62:788-791.

7. Izak, G., and K. Galewsky. 1966. Studies on experimentally induced hypercoagulable state in rabbits. Thrombos. Diath. Haemorrh. 16:228-242.

8. Wessler, S., S. N. Gitel, H. Bank, U. Martinowitz, and R. C. Stephenson. 1979. An assay of the antithrombotic action of warfarin: Its correlation with the inhibition of stasis thrombosis in rabbits. Thromb. Haemostasis. 40:486-498.

9. Gitel, S. N., and S. Wessler. 1979. The antithrombotic effects of warfarin and heparin following infusions of tissue thromboplastin in rabbits: clinical implications. J. Lab. Clin. Med. 94:481-488.

10. Gitel, S. N., and S. Wessler. 1983. Dose-dependent antithrombotic effect of warfarin in rabbits. Blood. 61:435-438.

11. Rao, L. V. M., and A. D. Hoang. 1989. Purification and characterization of rabbit brain tissue factor. Thromb. Res. 56:109-118.

12. Warr, T. A., L. V. M. Rao, and S. I. Rapaport. 1990. Disseminated intravascular coagulation in rabbits induced by administration of endotoxin or tissue factor: effect of anti-tissue factor antibodies and measurement of plasma extrinsic pathway inhibitor activity. Blood. 75:1481-1489.

13. Bajaj, S. P., S. I. Rapaport, and S. F. Brown. 1981. Isolation and characterization of human factor VII. J. Biol. Chem. 256:253-259.

14. Bajaj, S. P., S. I. Rapaport, and C. Prodanos. 1981. A simplified procedure for purification of human prothrombin, factor IX and factor X. Prep. Biochem. 11:397-412.

15. Rao, L. V. M., and A. D. Hoang. 1991. Purification and characterization of rabbit factor IX and its existence as a two-chain factor IX $\alpha$ in circulating plasma. Thromb. Res. 64:57-68.

16. Warr, T. A., L. V. M. Rao, and S. I. Rapaport. 1990. A sensitive, accurate assay for extrinsic pathway inhibitor (EPI) activity in rabbit plasma: paradoxical effect of excess exogenous factor X. Thromb. Res. 59:773-782.

17. Owren, P. A., and K. Aas. 1951. The control of dicumarol therapy and the quantitative determination of prothrombin and proconvertin. Scand. J. Clin. Lab. Invest. 3:201-208.

18. Clauss, A. 1957. Gerinnungs physiologishe schnell methode zue bestimmug des fibrinogens. Acta Haematol. 17:237-246.

19. Laemmli, U. K. 1970. Cleavage of structural proteins during the assembly of the head of bacteriophage T4. Nature (Lond.). 227:680-685.

20. Towbin, H., T. Staehelin, and J. Gordon. 1979. Electrophoretic transfer of proteins from polyacrylamide gels to nitrocellulose sheets: procedures and some applications. Proc. Natl. Acad. Sci. USA. 76:4350-4354.

21. Rapaport, S. I., and L. V. M. Rao. 1992. Initiation and regulation of tissue factor-dependent blood coagulation. Arterioscler. Thromb. 12:1111-1121.

22. Edwards, R. L., E. Schreiber, and W. Brande. 1986. The effect of sodium warfarin on rabbit monocyte tissue factor expression. Thromb. Res. 42:125-137.

23. Owren, P. A. 1955. Long-term dicumarol treatment in cardiovascular disease: technique and results. In International Conference on Thrombosis and Embolism, 1st. Basel, 1954. Schwabe \& Co. AG, Basel. 1085-1094.

24. Borchgrevink, C. F. 1960. Long-term anticoagulant therapy in angina pectoris and myocardial infarction: clinical trial of intensive versus moderate treatment. Acta Med. Scand. 168(Suppl. 359):1-52.

25. Zivelin, A. 1993. Individual importance of factors II, VII, IX and X for the antithrombotic effect of the vitamin $\mathrm{K}$ antagonist warfarin. Ph.D thesis. University of California, San Diego. 151 pp.

26. Loeliger, E. A., B. van der Esch, M. J. Mattern, and A. S. A. den Brabander. 1963. Behaviour of factors II, VII, IX, and X during long-term treatment with coumarin. Thrombos. Diath. Haemorrh. 9:74-89.

27. Strauss, H. S. 1965. Surgery in patients with congenital factor VII deficiency (congenital hypoproconvertinemia). Experience with one case and review of the literature. Blood. 25:325-334.

28. Briet, E., and G. Onvlee. 1987. Hip Surgery in a patient with severe factor VII deficiency. Haemostasis. 17:273-277.

29. Sandset, P. M., B. J. Warn-Cramer, L. V. M. Rao, S. L. Maki, and S. I Rapaport. 1991. Depletion of extrinsic pathway inhibitor (EPI) sensitizes rabbits to disseminated intravascular coagulation induced with tissue factor: evidence supporting a physiologic role for EPI as a natural anticoagulant. Proc. Natl. Acad. Sci. USA. 88:708-712.

30. Loeliger, E. A., B. van der Esch, C. C. ter Haar Romney-Watchter, and H. L. Booji. 1960. Factor VII: its turnover rate and its possible role in thrombogenesis. Thrombos. Diath. Haemorrh. 4:146-200.

31. Weiss, P., G. A. Soff, H. Halkin, and U. Seligsohn. 1987. Decline of proteins $\mathrm{C}$ and $\mathrm{S}$ and factors II, VII, IX and $\mathrm{X}$ during the initiation of warfarin therapy. Thromb. Res. 45:783-790.

32. Wessler, S., and S. N. Gitel. 1984. Warfarin: from bedside to bench. $N$. Engl. J. Med. 311:645-652.

33. Hyers, T. H., R. D. Hull, and J. G. Weg. 1992. Antithrombotic therapy for venous thromboembolic disease. Chest. 102 (Suppl.):409S-425S.

34. Williams, W. J. 1983. Life span of plasma coagulation factors. In Hematology, 3rd ed. W. J. Williams, E. Beutler, A. J. Erslev, and M. A. Lichtman, editors. McGraw-Hill Inc., New York. 1232-1237.

35. Braun, P. J., and K. M. Szewczyk. 1992. Relationship between total prothrombin, native prothrombin and the international normalized ratio(INR). Thromb. Haemostasis. 68:160-164. 